\title{
Improved performance and heightened neutrophil responses during the neonatal and weaning periods among outdoor group-housed Holstein calves
}

\author{
C. J. Cobb, ${ }^{\star}$ B. S. Obeidat, ${ }^{*}$ † M. D. Sellers, ${ }^{*}$ A. R. Pepper-Yowell, ${ }^{\star}$ D. L. Hanson, ${ }^{\star}$ and M. A. Ballou*1 \\ *Department of Animal and Food Sciences, Texas Tech University, Lubbock 79409 \\ †Department of Animal Production, Faculty of Agriculture, Jordan University of Science and Technology, Irbid 22110, Jordan
}

\begin{abstract}
The objective was to determine if outdoor group housing of Holstein calves influences metabolic status, leukocyte responses, and behavior compared with individually housed calves. Forty-nine Holstein heifer calves ( $2 \pm 1 \mathrm{~d}$ of age) were randomly assigned to 1 of 2 treatments: individually housed $(\mathrm{G} 1 ; \mathrm{n}=22)$ or group housed [3 calves per pen (G3); $\mathrm{n}=27$ ]. The space allowances per calf were 4.8 and $7.0 \mathrm{~m}^{2}$ for G1 and G3, respectively. All calves were offered an identical plane of milk replacer nutrition (747 and 1,010 g of $\mathrm{DM} / \mathrm{d}$ of a $28 \% \mathrm{CP}: 20 \%$ fat milk replacer from wk 1 to 2 and wk 3 to 6 , respectively). Weaning was initiated during wk 7 by removing the p.m. feeding and calves were completely weaned when they consumed $900 \mathrm{~g}$ of calf starter/d (as fed) for 2 consecutive days after d 54 . At d 90, calves were commingled into random outdoor groups of 5 calves per pen. Peripheral blood was collected during the neonatal (d 3, 10, and 21), weaning (d 46, 48, and 54), and commingling periods (d 90, 93, and 98) and was analyzed for neutrophil oxidative burst (OB) capacity when cocultured with Escherichia coli, neutrophil surface L-selectin protein expression, and whole-blood secretion of tumor necrosis factor- $\alpha$ when cocultured with lipopolysaccharide. Starter intake was greater for G3 during the postweaning period (wk 8 to 12). Average daily gain was greater for G3 than G1 from d 54 to 68 and tended to be greater after commingling from d 113 to 133. During the neonatal period, G3 calves had more activated neutrophils, as evidenced by increased neutrophil L-selectin protein expression and a tendency for increased percentage of neutrophils producing an OB than G1 calves. During weaning, G3 calves continued to have more activated neutrophils with increased L-selectin expression on d 46 and 48 and a greater $\mathrm{OB}$ intensity throughout the period. No differences were observed among leukocyte responses between treatments at d 93 and 98. Outdoor
\end{abstract}

Received April 8, 2013.

Accepted October 13, 2013

${ }^{1}$ Corresponding author: michael.ballou@ttu.edu group-housed Holstein calves had improved performance and heightened neutrophil responses compared with individually housed calves.

Key words: calf, housing, immune

\section{INTRODUCTION}

Passage of state and federal legislation has stressed the need to maintain gregariousness among animals early in life to preserve their natural behavior and potentially improve their welfare (Council of the European Union, 1997). Therefore, it is important to determine how and when dairy calves should be housed in groups. Animal grouping research is predominantly observational and performance based. A need exists for more data that determine the influence of calf housing on an animal's physiology and health before legislation determines how animals should be housed (Rushen, 1991).

Commingling of calves early in life was reported to increase calf starter intake (Warnick et al., 1977; De Paula Vieira et al., 2010), which could potentially result in healthier weaned animals. During commingling, animals are able to socialize and establish more natural responses to pen mates (Metz et al., 1986; Jensen et al., 1997; Chua et al., 2002). However, this system can create competition and more aggressive behavior within the pen (Andersen et al., 2004), leading to increased stress and dysfunctional behavior around humans (Györkös et al., 1999). This dysfunctional behavior is possibly caused by increased interaction and common associations with pen mates, resulting in excessive anxiety when approached by uncommon external stimuli. In addition, the transmission of microorganisms is increased by group housing (LeBlanc, 1981). Preweaned group-housed calves demonstrate cross-suckling and intersuckling that can result in the consumption of soil, hair, skin, and debris, leading to an increased risk for gastrointestinal upset (Broom, 1991; Redbo, 1992). Intersuckling, also termed milk stealing, when unsupervised and not discouraged, can lead to malnutrition in weaker calves and increased variability in the performance and health of calves in a herd (Lidfors and Isberg, 2003). 
The objectives of this experiment were to determine if outdoor-housed calves penned either individually or in small groups demonstrate differences in their performance, leukocyte responses, and behavioral characteristics during the neonatal, weaning, and commingling periods. It was hypothesized that grouphoused calves would (1) consume more calf starter and have an increased ADG as a result of competition or learned behaviors, or both, (2) the physical and behavioral interactions among group-housed calves would increase leukocyte responses, and (3) grouphoused calves would rely more on calf-to-calf than calf-human interactions.

\section{MATERIALS AND METHODS}

\section{Experimental Design and Calves}

All animal procedures were reviewed and approved by the Texas Tech University Animal Care and Use Committee. Forty-nine Holstein heifer calves $(2 \pm 1 \mathrm{~d}$ of age) were purchased and transported $78 \mathrm{~km}$ from a single commercial dairy farm and transported to the Hilmar Cheese and Agri-Plastics Calf Research Facility at Texas Tech University (New Deal, TX) in 4 enrollment groups over a 12-d period. All calves were fed 4 $\mathrm{L}$ of colostrum at the dairy within the first $12 \mathrm{~h}$ of life. Upon enrollment in the study, a peripheral blood sample was taken and individual total serum protein content was recorded using a hand-held refractometer (Atago USA Inc., Bellevue, WA). No differences were observed in total serum protein between groups and the sampled population average was $5.9 \pm 0.50 \mathrm{~g} / \mathrm{dL}( \pm \mathrm{SEM})$. Upon arrival at the research facility, calves were randomly assigned to either an outdoor individual hutch $(\mathbf{G} \mathbf{1} ; \mathrm{n}=$ 22 ) or outdoor hutches in 9 groups of 3 calves per pen (G3; $\mathrm{n}=27$ ). Individually penned calves were housed in $2.13 \times 1.09-\mathrm{m}$ commercial polyethylene calf hutches attached to $1.83 \times 1.09-\mathrm{m}$ uncovered pens with no bedding, whereas group-penned calves were housed in 2.26 $\times 2.69$-m commercial polyethylene hutches attached to $3.05 \times 4.88-\mathrm{m}$ uncovered pens with no bedding (AgriPlastics Inc., Tonawanda, NY). A total of 4 calves died during the study; 2 calves from each treatment. Three of those calves died during the first $3 \mathrm{~d}$ of life and their data were omitted before statistical analyses. Calves displaying symptoms of respiratory disease were treated with florfenicol-flunixin meglumine (Resflor Gold; Merck Animal Health, Summit, NJ), with 3 and 1 calves for G1 and G3, respectively, being treated. The minimum and maximum temperatures during the experimental period were 19.6 and $34.3^{\circ} \mathrm{C}$, respectively, and the average relative humidity, taken daily at 1000 h, was $44 \%$.

\section{Feeding, Weaning, and Measurements}

All calves were offered $747 \mathrm{~g}$ of $\mathrm{DM} / \mathrm{d}$ of a $28 \%$ protein and 20\% fat milk replacer (MR; Cow's Match Holstein Blend; Land O'Lakes Animal Products Co., Shoreview, MN; Table 1) during the first $2 \mathrm{wk}$ of life. The quantity of offered MR was increased to $1,010 \mathrm{~g}$ of $\mathrm{DM} / \mathrm{d}$ during wk 3 to weaning. Milk replacer was mixed with warm water $\left(43-48^{\circ} \mathrm{C}\right)$ to dissolve the powder and then mixed with cold water to reach the required volume at approximately $38^{\circ} \mathrm{C}$ and fed at $16.4 \% \mathrm{DM}$. The MR was offered to calves twice daily at 0800 and 1600 $\mathrm{h}$ for the duration of the study using plastic bottles with a nipple. Voluntary MR refusals were collected 15 min after each feeding. The research personnel limited intersuckling among group-housed calves by physically separating any calf that exhibited intersuckling. After the first week, all calves were offered ad libitum access to a pelleted calf starter (Table 1) and drinking water. Calf starter intake was recorded daily and adjusted for approximately a $10 \%$ refusal. No roughage was offered during the study. Weaning was orchestrated by block, with 2 enrollment groups in each weaning block. Weaning was started at d 46 by removing the 1600 -h milk bottle. Calves were weaned completely when daily consumption of calf starter exceeded $900 \mathrm{~g} / \mathrm{d}$ (as-fed basis) for 2 consecutive days after d 54 .

On d 90, all calves were randomly commingled into larger groups $(\mathrm{n}=5 /$ pen $)$ to simulate postweaning commingling growth performance. During this period (the grower phase), calves were fed $4.1 \mathrm{~kg}$ of concentrate pellets DM (AMPLI-Calf; Purina Mills LLC,

Table 1. The formulated nutrient content of the milk replacer and calf starter on a DM basis

\begin{tabular}{lcc}
\hline Nutrient & $\begin{array}{c}\text { Milk } \\
\text { replacer }\end{array}$ & $\begin{array}{c}\text { Calf } \\
\text { starter }^{1}\end{array}$ \\
\hline CP, \% & 28.0 & 20.0 \\
Ether extract, \% & 20.0 & 2.2 \\
Crude fiber, \% & 0.15 & 16.0 \\
ADF, \% & - & 18.0 \\
Calcium, \% & 1.0 & 1.0 \\
Phosphorus, \% & 0.70 & 0.50 \\
Selenium, mg/kg & - & 0.30 \\
Vitamin A, IU/kg & 44,000 & 7,700 \\
Vitamin $\mathrm{D}_{3}, \mathrm{IU} / \mathrm{kg}$ & 11,000 & - \\
Vitamin E, IU $/ \mathrm{kg}$ & 220 & - \\
\hline
\end{tabular}

${ }^{1}$ The calf starter (Cornerstone AMPLI-Calf) with monensin was fed using macro-ingredients, which included grain products, processed grain by-products, plant protein products, molasses, and roughage products (Purina Mills LLC, Gray Summit, MO). Also, the calf starter was formulated with a proprietary blend of a yeast extract, fructooligosaccharide, anise oil, garlic oil, cassia, ethyl vanillin, and propylene glycol. The trace mineral and vitamins used in the calf starter were mostly organic sources, including zinc amino acid complex, manganese amino acid complex, copper amino acid complex, cobalt glucoheptonate, and cobalt proteinate. 
Gray Summit, MO) per head per day and were offered alfalfa hay ad libitum. The hay and the concentrate were analyzed according to AOAC International (1995) procedures. The chemical composition for the concentrate was $97.3,22.4$, and $22.5 \% \mathrm{DM}, \mathrm{CP}$, and starch, respectively, whereas the hay contained 91.5, 16.2, 44.1, and $30.0 \%$ DM, CP, NDF, and ADF, respectively. The concentrate pellets were formulated with similar ingredients, micronutrients, and feed additives as the calf starter (Table 1).

\section{Daily Observations}

General disposition, appetite, and fecal scores were assessed twice daily. Calf disposition was classified as 1 $=$ normal, alert, quick response to human presence; $2=$ depressed, response to human presence decreased; $3=$ lethargic, response to human presence greatly reduced; and $4=$ morbid, little or no response to human presence (Ballou et al., 2011). Fecal scores were recorded according to the guidelines outlined by Larson et al. (1977). Scores were $1=$ firm, well-formed (not hard); 2 $=$ soft, pudding-like; $3=$ runny, similar in consistency to pancake batter; and $4=$ liquid, splatters, similar in consistency to pulpy orange juice. All fecal scores were recorded by observing fecal matter on the ground of the pen and on the tail and hind quarters of the calves. For group-housed calves, fecal scores were recorded as the average for the pen. All disposition and fecal score data were collected by 1 independent trained observer and averaged across 3 consecutive days before statistical analysis.

\section{Sampling and Blood Collection}

Before the morning feeding, each calf was weighed individually at enrollment and on d 10, 21, 54, 68, 90, 112,133 , and 161 of the study. Bone length from hoof to the scapula (height) and scapula to the pin (length) were measured to the nearest $0.2 \mathrm{~cm}$ with a tailor tape on the same days BW were recorded.

Nine milliliters of peripheral blood sample was collected from the jugular vein at d 3, 10, 21, 46, 48, 54, 90, 93, and 98 into 3 - and 6-mL evacuated tubes (Vacutainer; Becton Dickinson, Rutherford, NJ) containing $\mathrm{K}_{2}$ EDTA and heparin, respectively. The $\mathrm{K}_{2}$ EDTA tube was placed immediately on ice and the heparin tube was placed in an ice chest without ice (Sellers et al., 2013). Plasma from heparinized tubes were obtained after centrifugation at $1,200 \times g$ for $15 \mathrm{~min}$ at $23^{\circ} \mathrm{C}$ and stored frozen at $-40^{\circ} \mathrm{C}$ until subsequent analyses. Plasma glucose and urea nitrogen concentrations were analyzed by commercially available enzymatic, colorimetric kits (Stanbio Laboratory, Boerne, TX). Plasma haptoglobin concentrations were determined by measuring haptoglobin/hemoglobin complexes by the estimation of differences in peroxidase activity (Hulbert et al., 2011). All colorimetric data were measured on a SpectraMax 340PC (Molecular Devices LLC, Sunnyvale, CA). Control serum (Randox Laboratories, Oceanside, CA) was used to calculate the interassay coefficients of variation of 5.4 and $6.4 \%$ for plasma glucose and urea nitrogen, respectively. Intraassay coefficients of variation were 5.1 and $6.8 \%$ for plasma glucose and urea nitrogen, respectively. The intra- and interassay coefficients of variation for plasma haptoglobin were 1.4 and $3.4 \%$, respectively.

\section{Ex Vivo Immunological Analyses}

On d 3, 10, 21, 46, 48, 54, 90, 93, and 98, whole blood from the heparinized Vacutainer was diluted 1:4 in RPMI medium (Invitrogen Life Technologies, Grand Island, NY), with a final concentration of $1 \%$ antibiotic-antimycotic and $1 \mu \mathrm{g} / \mathrm{mL}$ of LPS (Escherichia coli 0111:B4; Sigma, St. Louis, MO). Cell suspensions were incubated for $24 \mathrm{~h}$ at $38^{\circ} \mathrm{C}$ in a humidified $5 \% \mathrm{CO}_{2}$ incubator. The supernatant was removed after the cell suspension was centrifuged at $1,200 \times g$ for $15 \mathrm{~min}$ at $23^{\circ} \mathrm{C}$ and stored at $-40^{\circ} \mathrm{C}$ until analysis of tumor necrosis factor- $\alpha$ concentration by a commercially available bovine-specific ELISA kit (R\&D Systems Inc., Minneapolis, MN). The oxidative burst (OB) capacities of whole-blood neutrophils in response to an enteropathogenic E. coli were analyzed as described by Hulbert et al. (2011). Briefly, $200 \mu \mathrm{L}$ of whole blood from the heparinized Vacutainer was incubated in an ice bath for $15 \mathrm{~min}$. Forty microliters of a $100 \mu M$ working concentration of dihydrorhodamine (Invitrogen Life Technologies) and the E. coli were added to each sample, vortexed thoroughly, and then placed in a $38.5^{\circ} \mathrm{C}$ water bath and incubated for 10 min. Immediately after the 10 min incubation, all samples were placed in an ice bath for $5 \mathrm{~min}$ to stop the reaction at a constant rate. Erythrocytes were hypotonically lysed and washed twice using $1 \times \mathrm{PBS}$, and then the leukocytes were analyzed using a Cell Lab Quanta SC flow cytometer (Beckman Coulter Inc., Fullerton, CA). Neutrophils were gated using flow cytometer analysis software (Quanta SC MPL; Beckman Coulter Inc.) on the scatterplot of electric volume $\times$ side scatter. The percentage of neutrophils that were positive for OB were gated as neutrophils that had a greater fluorescence intensity than neutrophils from control cultures that remained on ice during the incubation period. Data are reported as both the percentage of neutrophils positive for $\mathrm{OB}$ as well as the geometric mean fluorescence intensity of the positive neutrophil population. 
For quantification of neutrophil L-selectin expression, $200 \mu \mathrm{L}$ of whole blood from the EDTA Vacutainer was incubated in an ice bath for $1 \mathrm{~h}$ at a final dilution of $5 \mu \mathrm{g} / \mathrm{mL}$ of anti-bovine CD62L (monoclonal antibody IgG1-isotype made in mouse; VMRD, Pullman, WA). Erythrocytes were hypotonically lysed and then washed once using $1 \times$ PBS. The leukocyte pellet was resuspended in fluorescein-labeled secondary antibody at a 1:400 dilution $\left[\mathrm{F}\left(\mathrm{ab}^{\prime}\right) 2\right.$ anti-mouse IgG:FITC; AbD Serotec, Raleigh, NC]. Samples were incubated on ice for an additional $1 \mathrm{~h}$. Samples were then washed twice using $1 \times$ PBS and analyzed by single-color flow cytometry. Neutrophils were gated using the flow cytometer analysis software on the scatterplot of electric volume $\times$ side scatter. The total geometric mean fluorescence intensity for L-selectin was analyzed (Hulbert et al., 2011).

\section{Behavioral Observations}

Behavioral scoring was measured in 2 ways to determine social development and general response to stimuli of human interaction and isolation in a novel environment. Scores were given as a single observer stood in the far end of the pen with the animal (approach) on d 10, 21, 46, 48, 54, and 90: 1 = approaches individual with no hesitation; $2=$ hesitant but shows curiosity and slow approach; $3=$ sustains distance from individual; and $4=$ avoids individual and shows fear. This approach scoring system is a modified version of the method described by Lensink et al. (2003). When each calf was weighed in an isolated scale cage, a behavior score to a novel environment (scale) was recorded. This was a modified procedure to that described by Friend (1991). Briefly, each calf was scored as $1=$ displays frequent movement, turning, kicking, and excessive play on the scale; 2 = displays curiosity, frequent movement, play, and some turning on the scale; 3 = displays light pacing and moving on the scale; and $4=$ displays little or no movement, curiosity, or play on the scale.

\section{Statistical Analysis}

All repeated, continuous data were analyzed by restricted maximum-likelihood ANOVA using the PROC MIXED of SAS (v.9.2; SAS Institute Inc., Cary, NC). The covariance structures [compound symmetry and auto-regressive(1)] were tested for the within-subject measurements and the structure with the best fit was determined from the Bayesian information criteria. The model included the fixed effects of treatment, time, and treatment $\times$ time. The random effect included calf nested within treatment and pen. No enrollment group $\times$ treatment $\times$ time interaction was detected, so enrollment group was not included in the final statistical model. A Kenward-Roger correction was applied to the denominator degrees of freedom to obtain appropriate standard errors and $F$ statistics for each model. Prior to statistical analyses, the normality of residuals of repeated data was confirmed by evaluating the Shapiro-Wilk statistic using PROC UNIVARIATE of SAS. Pairwise differences were performed at each time interval using a sliced-effect multiple comparison approach with a Duncan's adjustment. Least squares means $( \pm \mathrm{SEM})$ are reported throughout. Categorical data, such as behavior scores, assumed a frequency with which the score occurred during an interval and were analyzed with a chi-squared test of homogeneity using PROC FREQ of SAS to determine differences in distributions between treatments for the given interval. Differences of $P<0.05$ were considered significant and $0.05 \leq P>0.10$ were considered a tendency.

\section{RESULTS}

\section{Performance}

No treatment or treatment $\times$ time interaction effect was observed on calf height and length throughout the study (data not shown). Calf starter intake for G1 and G3 calves was not different during the neonatal period, but G3 calves consumed more calf starter after weaning $(P<0.03$; Figure 1). Increased starter intake for G3 calves resulted in a tendency for greater $(P<0.099)$ ADG throughout the first $90 \mathrm{~d}$ of life, but sliced effects indicated the difference was observed immediately following weaning, from d 54 to $68(P<0.010$; Figure $2)$. No treatment $\times$ time $(P=0.509)$ or treatment $(P$ $=0.769)$ differences were observed in feed efficiency (feed:gain ratio) during the first $90 \mathrm{~d}$ of life. Once commingled into larger groups $(\mathrm{n}=5)$ at d 90, G3 calves tended $(P<0.072)$ to have greater ADG during d 113 to 133 (Figure 3).

\section{Calf Health and Immune Response}

The G1 calves had softer stools during the acclimation period on d 1 to $6(P<0.0002)$, whereas G3 calves had softer stools on d 6 to 9,24 to 27,30 to 33 , and 42 to $45(P<0.015)$, as well as a tendency $(P<0.097)$ for higher fecal scores on d 15 to 18 and 27 to 30 (Figure 4).

Throughout the neonatal period, G3 calves had greater $(P<0.047)$ L-selectin protein expression on the surface of neutrophils than G1 calves (Figure 5). A treatment $\times$ time interaction $(P<0.001)$ effect was observed on L-selectin protein expression around weaning, being greater $(P<0.011)$ in G3 calves at d 46 and 


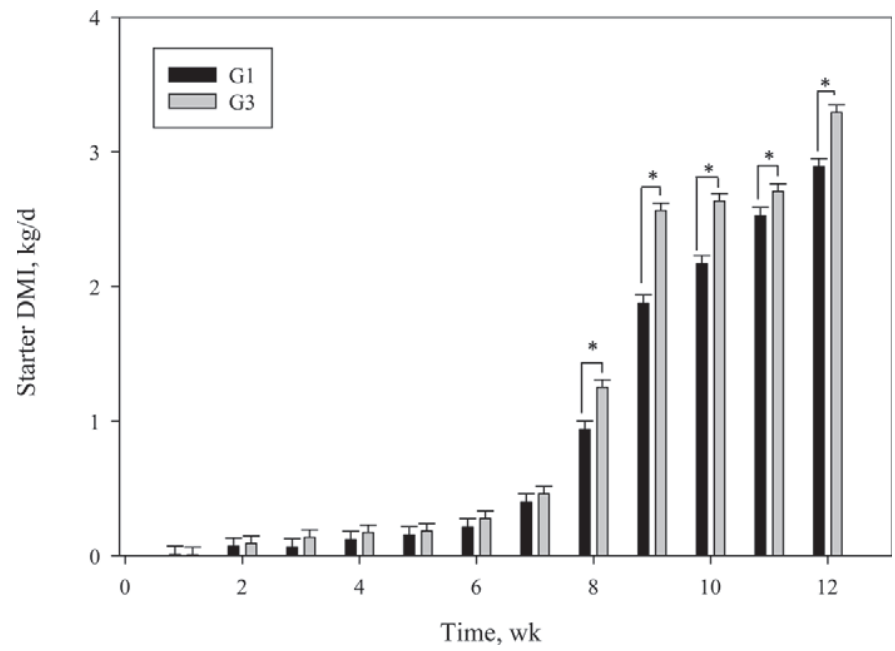

Figure 1. Effect of outdoor pen population on starter intake symbolizes weaning at wk 7 . Treatment $\times$ time: $P<0.05$; sliced effects: ${ }^{*} P<0.05$. G1 = outdoor individual hutch; G3 = outdoor group of 3. Error bars represent SEM.

48, but G1 calves tended $(P<0.097)$ to be greater at $\mathrm{d}$ 54. Immediately before commingling at d 90, G3 calves tended $(P<0.092)$ to have greater L-selectin protein expression, but following commingling, no difference $(P$ $=0.362)$ was observed between treatments.

During the neonatal period, a treatment $\times$ time interaction $(P<0.002)$ was observed, with G3 calves having greater neutrophil OB intensity at d 10 (Figure 6). In addition, around weaning, G3 calves continued to have greater $(P<0.001)$ neutrophil OB intensity. No differences $(P=0.517)$ were observed in the neutrophil

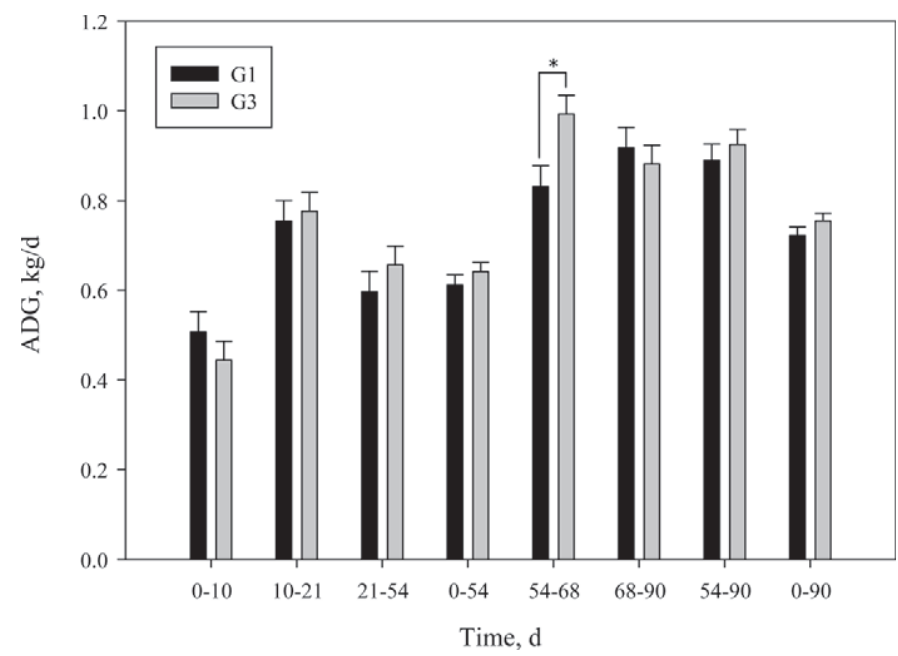

Figure 2. Effect of outdoor pen population on ADG during precommingling (d 0-54,54-90, and 0-90 analyzed separately with oneway ANOVA). Treatment $\times$ time: $P=0.10$; sliced effects: ${ }^{*} P<0.05$. G1 = outdoor individual hutch; G3 = outdoor group of 3. Error bars represent SEM.

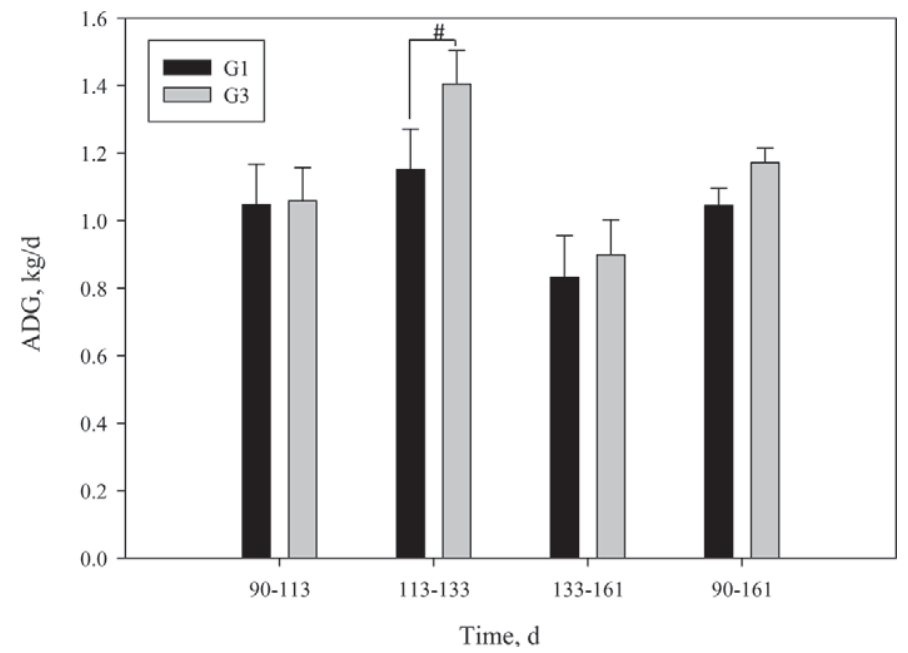

Figure 3. Effect of outdoor pen population on ADG during commingling (d 90-161 analyzed separately with one-way ANOVA). Treatment $\times$ time: $P>0.10$; sliced effects: $\# P<0.10$. G1 $=$ outdoor individual hutch; G3 = outdoor group of 3. Error bars represent SEM.

OB intensity either immediately before or after commingling of calves at d 90. Plasma concentrations of tumor necrosis factor- $\alpha$ and haptoglobin were similar $(P>0.20)$ between treatments throughout the study (Table 2).

During the neonatal period, plasma glucose concentration was greater $(P<0.048)$ in G1 calves compared with G3 calves (Table 2). During the weaning period, a tendency $(P<0.096)$ existed for a treatment $\times$ time interaction effect on plasma urea nitrogen concentrations to be greater among G3 calves. Throughout the com-

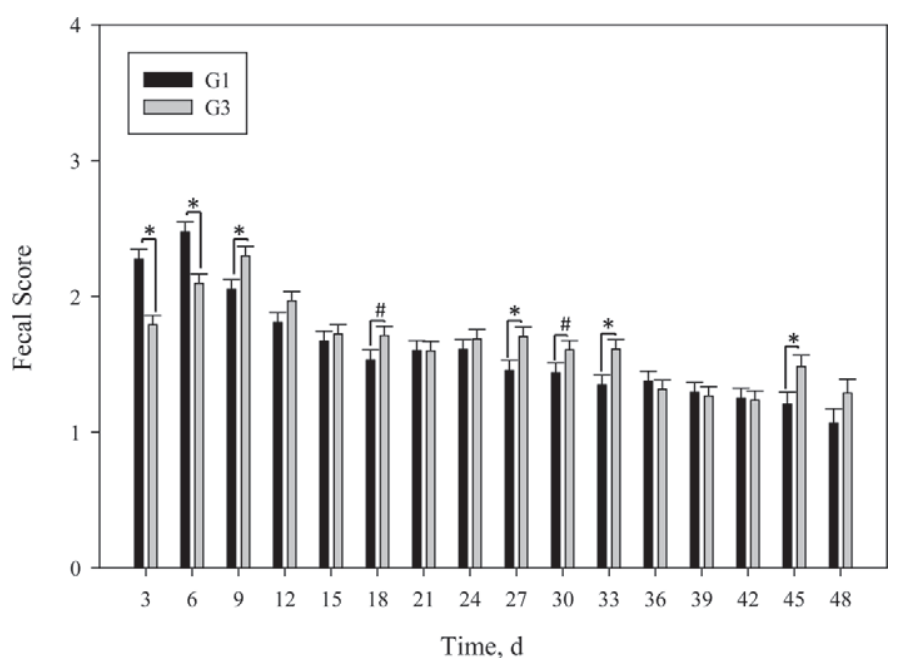

Figure 4. Effect of outdoor pen population on fecal score. Treatment $\times$ time: $P<0.05$; sliced effects: ${ }^{*} P<0.05$ and $\# P<0.10$. G1 $=$ outdoor individual hutch; G3 = outdoor group of 3. Error bars represent SEM. 


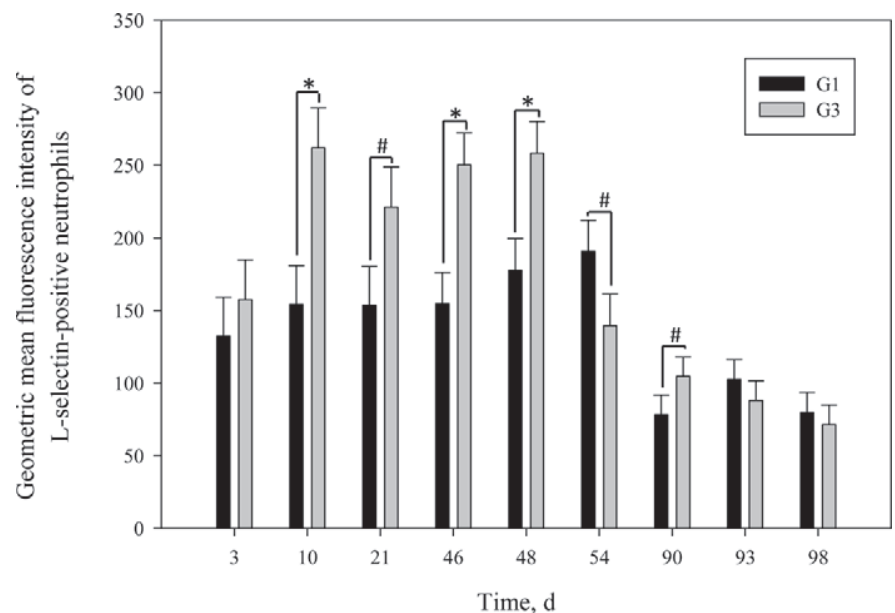

Figure 5. Effect of outdoor pen population on geometric mean fluorescence intensity of L-selectin-positive neutrophils [d 3, 10, and 21 (neonatal period); 45, 47, and 53 (weaning period); and 90 (immediate postweaning)]. Treatment $\times$ time: $P<0.05$; sliced effects: ${ }^{*} P<0.05$ and $\# P<0.10$. G1 = outdoor individual hutch; G3 = outdoor group of 3. Error bars represent SEM.

mingling period, a tendency $(P<0.058)$ existed for G3 calves to have greater plasma glucose concentrations.

\section{Behavior}

Frequency distributions of approach scores during the neonatal period for G1 and G3 calves tended $(P$ $<0.070$ ) to be different at d 10 (Figure 7 ), but were not different at d $21(P=0.31)$. All approach score frequency distributions around weaning (d 46 to 54) and at d 90 were different $(P \leq 0.047)$. Frequency distributions of scale scores for calves were different at all

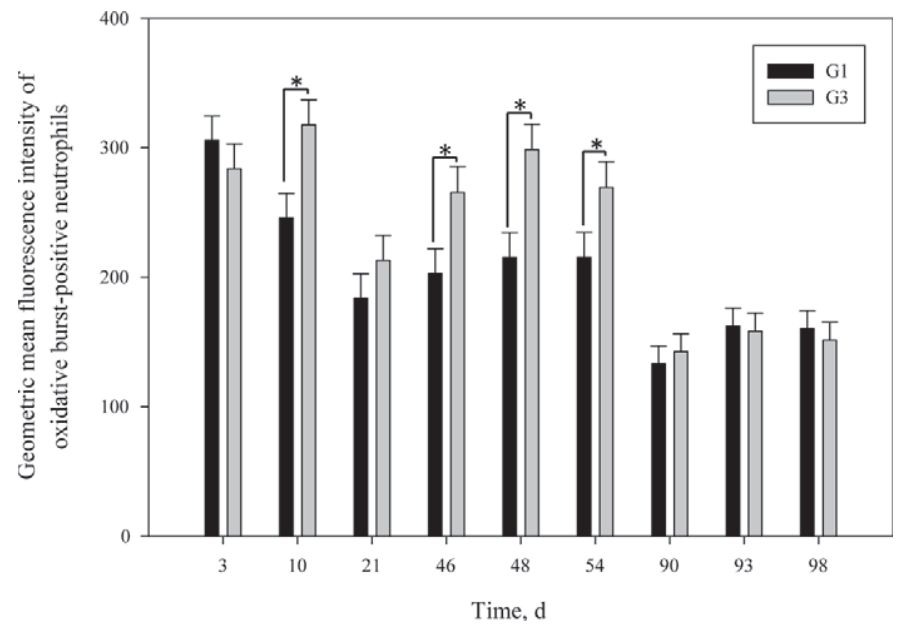

Figure 6. Effect of outdoor pen population on geometric mean fluorescence intensity of oxidative burst-positive neutrophils [d 3, 10, and 21 (neonatal period); 45, 47, and 53 (weaning period); and 90 (immediate postweaning)]. Treatment $\times$ time: $P<0.05$; sliced effects: ${ }^{*} P<0.05$. G1 = outdoor individual hutch; G3 = outdoor group of 3. Error bars represent SEM.

times after d $10(P \leq 0.001$; Figure 8$)$, showing that G3 calves moved or explored less when placed on the weighing scale compared with G1 calves.

\section{DISCUSSION}

\section{Performance}

All calves had increased calf starter intake during the postweaning period, but G3 calf intake increased more than G1, possibly either due to learned behaviors or competition by pen mates (Babu et al., 2004). Warnick

Table 2. Effects of outdoor pen population on blood metabolites of Holstein calves

\begin{tabular}{|c|c|c|c|c|c|}
\hline \multirow[b]{2}{*}{ Blood metabolite $^{1}$} & \multicolumn{3}{|c|}{ Treatment $^{2}$} & \multicolumn{2}{|c|}{ Effect, $P$-value } \\
\hline & G1 & G3 & $\begin{array}{l}\text { Largest } \\
\text { SEM }\end{array}$ & Treatment & $\begin{array}{l}\text { Treatment } \\
\quad \times \text { time }\end{array}$ \\
\hline \multicolumn{6}{|l|}{ Neonatal } \\
\hline TNF- $\alpha, p g / m L$ & 841 & 880 & 72.6 & 0.70 & 0.39 \\
\hline Plasma urea nitrogen, $\mathrm{mg} / \mathrm{dL}$ & 10.7 & 11.3 & 0.97 & 0.58 & 0.34 \\
\hline Glucose, mg/dL & 83.5 & 79.5 & 3.00 & 0.048 & 0.10 \\
\hline \multicolumn{6}{|l|}{ Weaning } \\
\hline TNF- $\alpha, p g / m L$ & 1,174 & 991 & 156.9 & 0.20 & 0.57 \\
\hline Plasma urea nitrogen, mg/dL & 9.9 & 10.3 & 0.44 & 0.55 & 0.096 \\
\hline Glucose, $\mathrm{mg} / \mathrm{dL}$ & 83.3 & 80.9 & 1.87 & 0.14 & 0.91 \\
\hline Haptoglobin, OD × 100 & 1.04 & 0.98 & 0.055 & 0.38 & 0.43 \\
\hline \multicolumn{6}{|l|}{ Commingling } \\
\hline TNF- $\alpha, \mathrm{pg} / \mathrm{mL}$ & 1,012 & 1,044 & 107.3 & 0.82 & 0.90 \\
\hline Plasma urea nitrogen, $\mathrm{mg} / \mathrm{dL}$ & 14.7 & 15.5 & 1.55 & 0.34 & 0.72 \\
\hline
\end{tabular}

${ }^{1} \mathrm{OD}=$ optical density.

${ }^{2}$ Treatments were either an outdoor individual hutch $(\mathrm{G} 1 ; \mathrm{n}=22)$ or an outdoor group of $3(\mathrm{G} 3 ; \mathrm{n}=27)$. 


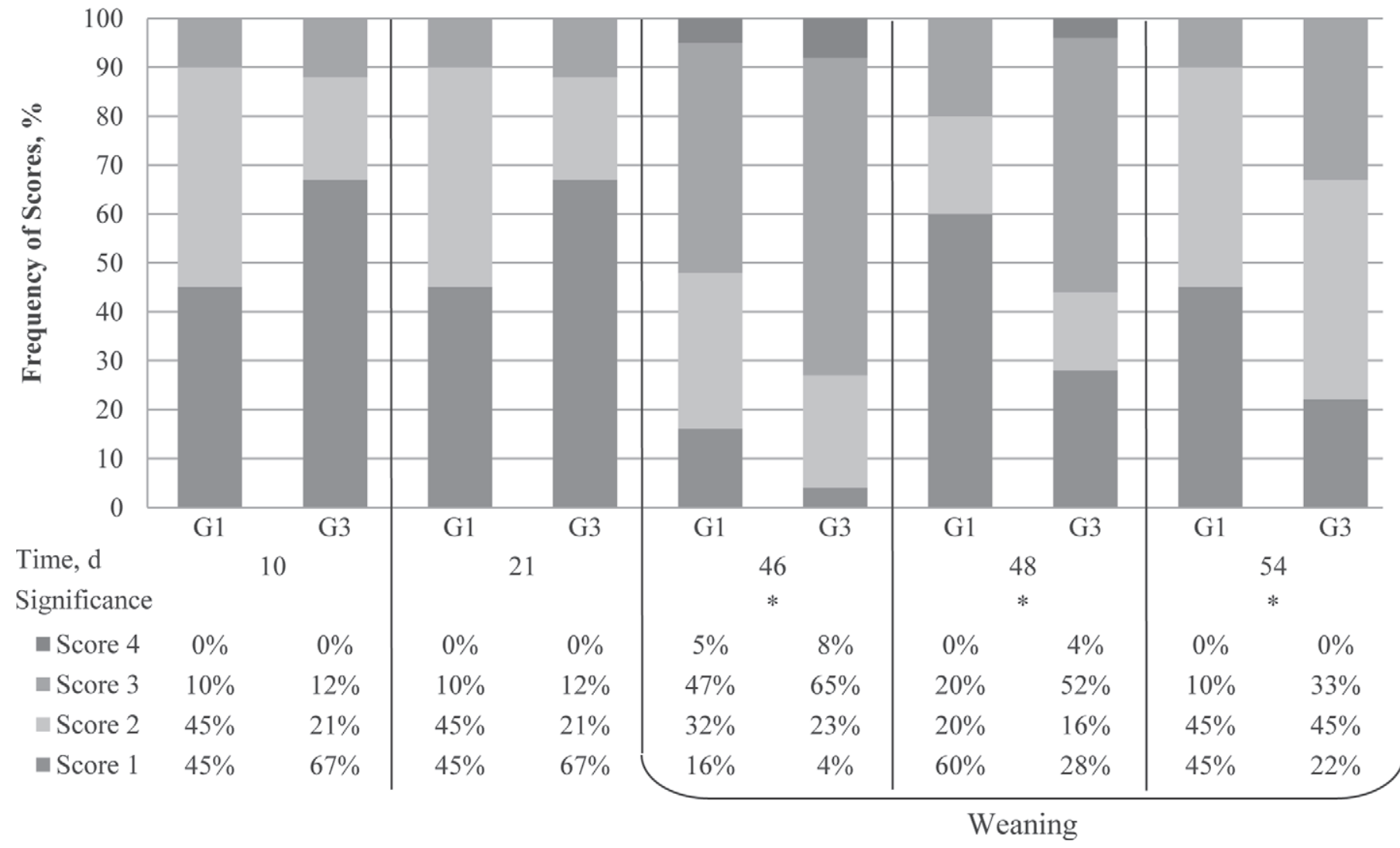

Figure 7. Effect of outdoor pen population on approach score behavior [d 10 and 21 (neonatal period); 46, 48, and 54 (weaning period); and 90 (immediate postweaning)]. Statistical significance: ${ }^{*} P<0.05$. Approach score: $1=$ approaches individual with no hesitation; $2=$ hesitant but shows curiosity and slow approach; $3=$ sustains distance from individual; $4=$ avoids individual and shows fear. G1 = outdoor individual hutch; G3 = outdoor group of 3 .

et al. (1977) and De Paula Vieira et al. (2010) observed that group-housed calves fed a high plane of nutrition consumed more calf starter during the neonatal period compared with single-housed calves, whereas in the current study, the greater starter intake was reserved for the postweaning period. The increased starter intake of G3 calves improved the immediate postweaning ADG without affecting feed efficiency, which was also reported by De Paula Vieira (2008). The advantage of greater starter intake during weaning and postweaning can lead to more rapid rumen development and a potentially larger or healthier calf that can enter the breeding pen at a younger age (Warner et al., 1956; Porter et al., 2007). It was of interest to examine the ADG of G1 and G3 calves once randomly commingled into larger groups of calves, as Hulbert and Ballou (2012) reported reduced performance and elevated total leukocyte counts when individually housed calves were commingled $28 \mathrm{~d}$ after weaning. In the current study, a tendency existed for an improved ADG noted among G3 calves to be maintained during d 90 to 161 . Taken together, these data suggest that a previously group-penned calf may transition to commingling with a novel group of calves more smoothly.

\section{Calf Health and Immune Response}

Individually housing calves during the preweaning period is an effective management tool to reduce the horizontal transmission of diseases. Numerous data have reported an increased morbidity and mortality among group-housed calves compared with calves housed individually (Fourichon et al., 1997; Losinger and Heinrichs, 1997; Gulliksen et al., 2009). In addition, individually housing calves does not allow either cross- or intersuckling among calves, which can have both immediate and long-term effects that are detrimental to an animal's wellbeing. Although G3 calves in the current study had slightly greater fecal scores after d 9, the incidences of scours in both treatments (consecutive days with fecal score 3 or 4 ) were negligible after the second week of life. With the exception of mild scouring during the first 2 wk of life, the calves in this study were clinically healthy. Plasma haptoglobin concentrations, a measure 


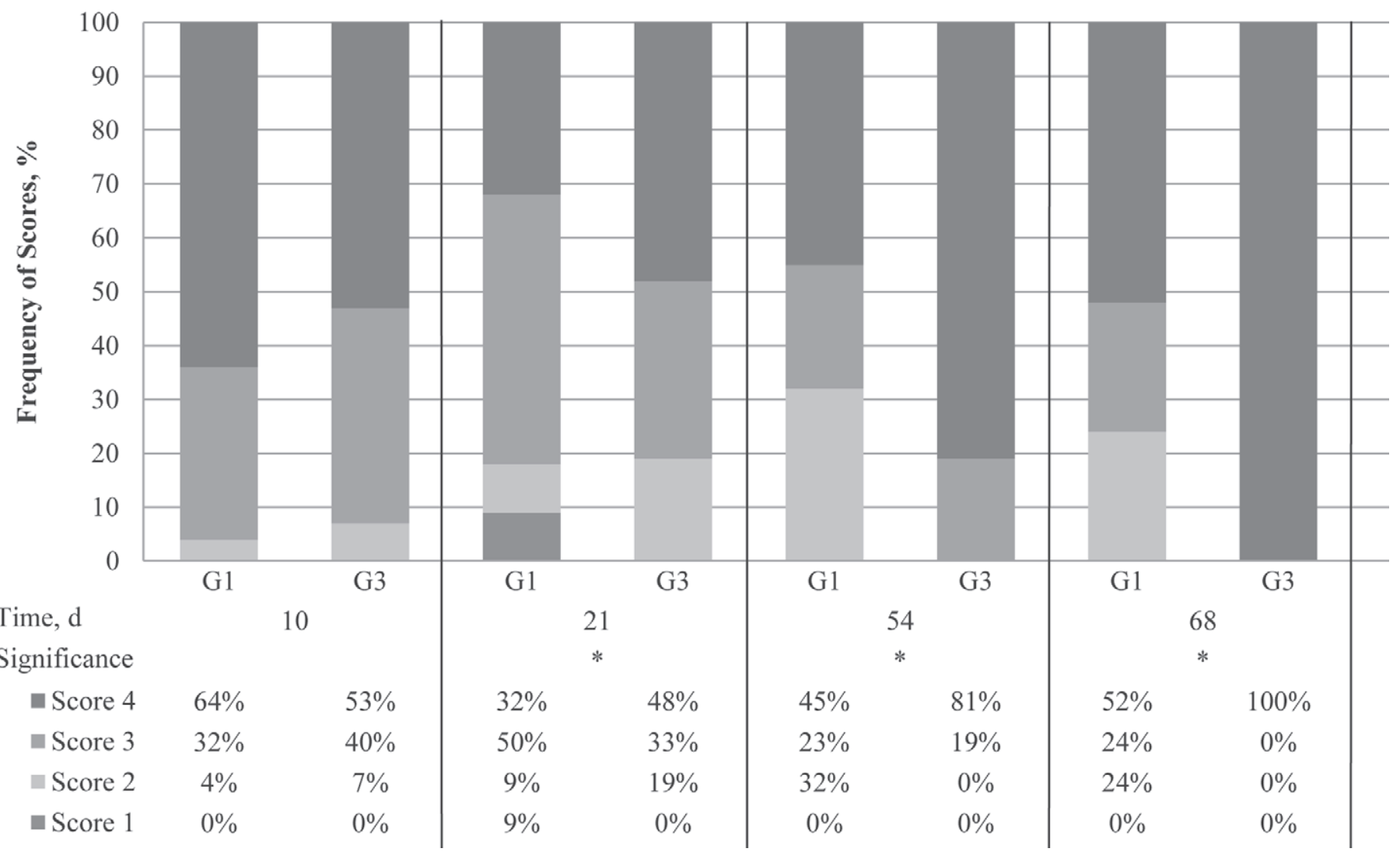

Figure 8. Effect of outdoor pen population on scale score [d 10 and 21 (neonatal period) and d 54, 68, and 90 (postweaning)]. Statistical significance: ${ }^{*} P<0.05 .1=$ displays frequent movement, turning, kicking, and excessive play on the scale; $2=$ displays curiosity, frequent movement, play, and some turning on the scale; $3=$ displays light pacing and moving on the scale; $4=$ displays little or no movement, curiosity, or play on the scale. G1 = outdoor individual hutch; G3 = outdoor group of 3.

of systemic inflammation, were low and not different between treatments throughout the entire study. Taken together with the performance data, these data further support that the calves, irrespective of housing treatment in this study, were healthy. In agreement, Hulbert and Ballou (2012) also reported no difference in plasma haptoglobin between calves that were commingled 28 $\mathrm{d}$ after weaning in groups of 3 or calves that remained individually housed. Further, Hänninen et al. (2003) actually reported lower incidences of scours when calves were housed in groups compared with individual pens. Therefore, calves can be raised together in groups without increasing morbidity and mortality; however, this likely depends highly on the microbial pressure of the environment in which the calves are raised.

The neutrophil responses, surface expression of Lselectin, and oxidative burst in response to $E$. coli evaluated in this study were greater among G3 calves during much of the preweaning period. The exact mechanism(s) causing the greater neutrophil responses among G3 calves cannot be determined from the present data, but it is likely multifactorial. In agreement with the present study, Hulbert and Ballou (2012) reported that total leukocyte counts increased when calves were commingled $28 \mathrm{~d}$ after weaning. Those authors suggested that the leukocytosis of the grouped calves was due to an increased immunogenic stimulation from the new environment or through direct contact with novel calves. The leukocytosis reported by Hulbert and Ballou (2012) and the more active neutrophil responses in the present study were in the absence of elevated plasma haptoglobin concentrations or clinical signs of disease. Data from rodents indicate that the microbiome of the gastrointestinal tract, without causing disease, affects neutrophil activity (Ohkubo et al., 1999; Clarke et al., 2010). Future research on group housing should investigate whether differences occur in microbial pressure and the microbiome of those calves compared with individually housed calves. The implications of this could have long-term effects on the immune system of an animal, as the early life microbiome of humans and rodents influenced immune responses later in life (Falk et al., 1998).

Reduced stress among group-housed calves could also explain the greater neutrophil responses, as many stressors were reported to decrease neutrophil respons- 
es in calves (Burton et al., 1995). Hulbert and Ballou (2012) observed that calves that were commingled in groups of 3 had lower concentrations of plasma cortisol than calves that continued to be housed individually. In addition, Chua et al. (2002) reported that calves raised in pairs continued to gain $\mathrm{BW}$ during the week of weaning, whereas individually housed calves lost weight that week. Weaning is known to be stressful; therefore, it is has been hypothesized that group-housed calves are able to cope better to some stressors (Chua et al., 2002). More research is needed to describe how group housing and social interactions among pen mates influences the response to stressors.

\section{Behavior}

During the neonatal period, approach and scale scores were determined by the reaction of calves to an observer standing in the pen and to a novel environment (being placed into the scale cage alone outside of the pen), respectively. During the neonatal period, calves of both housing treatments were eager to approach the observer. It can be determined that at this time most dairy calves relate humans with milk feeding and voluntarily approach, showing no established response indicative of fear. Many G3 calves showed little to no movement on the scale during the neonatal period, whereas G1 calves began to exhibit play and curiosity toward the end of the neonatal period. Stressed animals may exhibit lack of responsiveness and interest to new surroundings, whereas more comfortable calves will usually demonstrate exploratory movement (Friend, 1991). Therefore, our data suggest that G1 calves were more comfortable in a novel environment during the end of the neonatal period. In agreement, Dellmeier et al. (1985) found that when previously group-housed calves were placed in a novel environment, they exhibited less interaction with the environment and alien calves by not displaying locomotion, defense, or engaging in social behavior; with physiological data indicating that grouped calves were experiencing chronic stress.

Although G3 calves became more approachable throughout weaning, likely due to restriction of MR, more G3 calves sustained distance from the observer compared with G1 calves. The G3 calves demonstrated more behavioral characteristics suggestive of fright or stress (Friend, 1991) when in the scale cage compared with G1 calves. In conclusion, it can be surmised that G3 calves were not as sociable with humans as G1 calves even during weaning, showing that group-housed calves rely more on interactions with pen mates than with farm animal attendants throughout the weaning period. Györkös et al. (1999) reported data that would support this hypothesis, as they found that group- housed calves are more difficult to handle, have more interactions with pen mates, and became easier to handle with more human involvement.

Lacking human interaction during the postweaning period, most G3 calves seldom exhibited play or curiosity with a novel surrounding, whereas more G1 calves paced or showed moderate movement in the scale test. Group-housed calves act frightened when approached and in a novel environment after acclimation as a result of a lack of human interaction (Lensink et al., 2001) and constant association with their environment and pen mates, an effect that can last for years (Broom and Leaver, 1978).

\section{CONCLUSIONS}

Calves raised in outdoor groups had increased calf starter intake and ADG during the postweaning period compared with individually outdoor-housed calves, which may be due to learned behaviors or competition among calves in a pen. This social and physical interaction among calves likely increases subsequent exposure to microorganisms or reduces stress that may explain the greater neutrophil L-selectin expression and OB capacities. Future research is needed to understand the mechanisms of the heightened neutrophil responses during the preweaning period, as well as its implications on the subsequent immune responses of the calves. Grouping calves, even in small groups of 3, increased their interaction and reliance on pen mates, but this was not noted until after 3 wk of life.

\section{ACKNOWLEDGMENTS}

The authors acknowledge the milk replacer donations and feeding recommendations made by Land O'Lakes Animal Milk Products Co. (Shoreview, MN).

\section{REFERENCES}

Andersen, I. L., E. Naevdal, M. Bakken, and K. E. Bøe. 2004. Aggression and group size in domesticated pigs, Sus scrofa: When the winner takes it all and the loser is standing small. Anim. Behav. 68:965-975.

AOAC International. 1995. Official Method of Analysis. 16th ed. AOAC International, VA.

Babu, L. K., H. N. Pandey, and A. Sahoo. 2004. Effect of individual versus group rearing on ethological and physiological responses of crossbred calves. Appl. Anim. Behav. Sci. 87:177-191.

Ballou, M. A., C. J. Cobb, L. E. Hulbert, and J. A. Carroll. 2011. Effects of intravenous Escherichia coli dose on the pathophysiology response of colostrum-fed Jersey calves. Vet. Immunol. Immunopathol. 141:76-83.

Broom, D. 1991. Needs and welfare of housed calves. Pages 23-31 in New Trends in Veal Calf Production. Proceedings of the International Symposium on Veal Calf Production. J. H. M. Metz and C. M. Groenestein, ed. EAAP Publications, Pudoc, Wageningen, the Netherlands. 
Broom, D. M., and J. D. Leaver. 1978. Effects of group-rearing or partial isolation on later social behaviour of calves. Anim. Behav. 26:1255-1263.

Burton, J. L., M. E. Kehrli Jr., S. Kapil, and R. L. Horst. 1995. Regulation of L-selectin and CD18 on bovine neutrophils by glucocorticoids: Effects of cortisol and dexamethasone. J. Leukoc. Biol. 57:317-325.

Chua, B., E. Coenen, J. van Delen, and D. M. Weary. 2002. Effects of pair versus individual housing on the behavior and performance on dairy calves. J. Dairy Sci. 85:360-364.

Clarke, T. B., K. M. Davis, E. S. Lysenko, A. Y. Zhou, Y. Yu, and J. N. Weiser. 2010. Recognition of peptidoglycan from the microbiota by Nod1 enhances systemic innate immunity. Nat. Med. $16: 228-231$

Council of the European Union. 1997. Council Directive 97/2/EC of 20 January 1997 amending Directive 91/629/EEC laying down minimum standards for the protection of calves. Off. J. L025:24-25.

De Paula Vieira, A., M. A. G. von Keyserlingk, and D. M. Weary. 2010. Effects of pair versus single housing on performance and behavior of dairy calves before and after weaning from milk. J. Dairy Sci. 93:3079-3085.

De Paula Vieira, A., V. Guesdon, A. M. de Passillé, M. A. G. von Keyserlingk, and D. M. Weary. 2008. Behavioural indicators of hunger in dairy calves. Appl. Anim. Behav. Sci. 109:180-189.

Dellmeier, G. R., T. H. Friend, and E. E. Gbur. 1985. Comparison of four methods of calf confinement. II. Behavior. J. Anim. Sci. 60:1102-1109.

Falk, P. G., L. V. Hooper, T. Midtvedt, and J. I. Gordon. 1998. Creating and maintaining the gastrointestinal ecosystem: What we know and need to know from gnotobiology. Microbiol. Mol. Biol. Rev. 62:1157-1170.

Fourichon, C., F. Beaudeau, and H. Seegers. 1997. Critical points related to housing and management in control programmes for calf morbidity and mortality in French dairy herds. Pages 32-35 in 9th Int. Congr. Anim. Hygiene. International Society for Animal Hygiene (ISAH), Helsinki, Finland.

Friend, T. H. 1991. Behavioral aspects of stress. J. Dairy Sci. 74:292303

Gulliksen, S. M., K. I. Lie, T. Løken, and O. Østerås. 2009. Calf mortality in Norwegian dairy herds. J. Dairy Sci. 92:2782-2795.

Györkös, I., M. Mézes, E. Szücs, K. Kovács, G. Borka, G. Gábor, and J. Völgyi-Csík. 1999. Behavioural development of Holstein-Friesian cows and calves. Acta Agronomica Hungarica 41:39-52.

Hänninen, L., H. Hepola, J. Rushen, A. M. de Passillé, P. Pursiainen, V.-M. Tuure, L. Syrjälä-Qvist, M. Pyykkönen, and H. Saloniemi. 2003. Resting behavior, growth and diarrhoea incidence rate of young dairy calves housed individually or in groups in warm or cold buildings. Acta Agric. Scand. A Anim. Sci. 53:21-28.

Hulbert, L. E., and M. A. Ballou. 2012. Innate immune responses and on health of individually reared Holstein calves after placement into transition-pens $23 \mathrm{~d}$ after weaning. J. Dairy Res. 79:333-340.

Hulbert, L. E., C. J. Cobb, J. A. Carroll, and M. A. Ballou. 2011. The effects of weaning on innate immune responses of Holstein calves. J. Dairy Sci. 94:2545-2556.
Jensen, M. B., K. S. Vestergaard, C. C. Krohn, and L. Munksgaard. 1997. Effect of single versus group housing and space allowance on responses of calves during open-field tests. Appl. Anim. Behav. Sci. 54:109-121.

Larson, L. L., F. G. Owen, J. L. Albright, R. D. Appleman, R. C. Lamb, and L. D. Muller. 1977. Guidelines toward more uniformity in measuring and reporting calf experimental data. J. Dairy Sci. 60:989-991.

LeBlanc, M. M. 1981. Management of calf herd programs. Vet. Clin. North Am. Large Anim. Pract. 3:435-445.

Lensink, B. J., S. Raussi, X. Boivin, M. Pyykkönen, and I. Veissier. 2001. Reactions of calves to handling depend on housing condition and previous experience with humans. Appl. Anim. Behav. Sci. 70:187-199.

Lensink, B. J., C. G. van Reenen, B. Engel, T. B. Rodenburg, and I. Veissier. 2003. Repeatability and reliability of an approach test to determine calves' responsiveness to humans: "A brief report". Appl. Anim. Behav. Sci. 83:325-330.

Lidfors, L., and L. Isberg. 2003. Intersuckling in dairy cattle-Review and questionnaire. Appl. Anim. Behav. Sci. 80:207-231.

Losinger, W. C., and A. J. Heinrichs. 1997. Management practices associated with high mortality among preweaned dairy heifers. J. Dairy Res. 64:1-11.

Metz, J. H. M., H. K. Wierenga, F. J. Grommers, and R. G. Buré. 1986. The wellbeing of cattle under practical management conditions (English summary). Rapport van de Werkgroep Welzijn Rundvee. Veterinaire Dienst, Ministerie van Landbouw en Visserji, Den Haag, the Netherlands.

Ohkubo, T., M. Tsuda, S. Suzuki, N. El Borai, and M. Yamamura. 1999. Peripheral blood neutrophils of germ-free rats modified by in vivo granulocyte-colony-stimulating factor and exposure to natural environment. Scand. J. Immunol. 49:73-77.

Porter, J. C., R. G. Warner, and A. F. Kertz. 2007. Effect of fiber level and physical form of starter on growth and development of dairy calves fed no forage. Prof. Am. Sci. 23:395-400.

Redbo, I. 1992. Stereotypies in dairy cattle and their relation to confinement, production-related factors, physiological reactions, and adjoining behaviours. PhD Diss. Department of Animal Nutrition and Management, Swedish University of Agricultural Sciences, Uppsala, Sweden.

Rushen, J. 1991. Problems associated with the interpretation of physiological data in the assessment of animal welfare. Appl. Anim. Behav. Sci. 28:381-386

Sellers, M. D., L. E. Hulbert, and M. A. Ballou. 2013. Technical note: Determination of preanalysis storage temperature and time allowances for ex vivo innate immune responses. J. Dairy Sci. 96:384389.

Warner, R. G., W. P. Flatt, and J. K. Loosli. 1956. Dietary factors influencing the development of the ruminant stomach. J. Agric. Food Chem. 4:788-792.

Warnick, V. D., C. W. Arave, and C. H. Mickelsen. 1977. Effects of group, individual, and isolated rearing of calves on weight gain and behavior. J. Dairy Sci. 60:947-953. 